\title{
Autoimmune Neutropenia in Infancy Due to Anti- NA1 Antibody: Detection of Antibody with Immunofluorescence and Agglutination Test
}

\author{
MASAO KOBAYASHI, CHIMAKO YUMIBA, TAKASHI SATOH, TOSHINARI MARUKO, \\ TAKAMASA KISHI, YOSHINORI KAWAGUCHI, YOSHITO TANAKA, KAZUHIRO UEDA, \\ YOSHITAKA KOMAZAWA, MIYUKI KANEDA, MISAE TANIHIRO, AND KOHSUKE OKADA \\ Department of Pediatrics [M. Kobayashi, C.Y., T.S., T.M., T.K., Y. Kawaguchi, Y.K., Y.T., K.U.] and \\ Department of Blood Transfusion [Y. Komazawa, M. Kaneda, M.T., K.O.J, Hiroshima University School of \\ Medicine, Kasumi Minami-ku, Hiroshima, Japan
}

\begin{abstract}
The sera from two patients with chronic neutropenia in infancy were examined for the presence of antineutrophil antibodies and their specificity against neutrophil antigen by using granulocyte indirect immunofluorescence test and microleukocyte agglutination test. In the microleukocyte agglutination test, the patients' sera reacted with neutrophils from their parents and normal unrelated donors having the neutrophil antigen NA1, but not with neutrophils from $\mathrm{NA1}^{-}$donors. After the absorption of patients' sera with $\mathrm{NA1}^{+}$neutrophils, the antibody activity was completely abolished, resulting in the confirmation of the anti-NA1 antibody. In contrast, the granulocyte indirect immunofluorescence test showed positive reactions against both $\mathrm{NA1}^{+}$and $\mathrm{NA1}^{-}$neutrophils, and the specificity for anti-NA1 was found in the results of the sera absorbed with $\mathrm{NA1}^{+}$neutrophils. This suggested that the absorption experiment might be necessary to determine the specificity of the antibody for neutrophil antigen. Thus, we confirmed two cases with autoimmune neutropenia caused by anti-NA1 antibody. A combination of agglutination and immunofluorescence techniques would be recommended for investigation of neutrophil antibodies against the neutrophil-specific antigen. (Pediatr Res 26:246-249, 1989)
\end{abstract}

\section{Abbreviations}

GIIFT, granulocyte indirect immunofluorescence test M-LAT, microleukocyte agglutination test

ANC, absolute neutrophil count

CFU, colony-forming units

WBC, white blood cells

\footnotetext{
Autoimmune neutropenia of infancy appears to be one of the common features of neutropenia in childhood (1-3). Antineutrophil antibodies are well identified by using recently developed techniques, such as leukoagglutination test, indirect immunofluorescence test, and granulocyte cytotoxicity assay. Although antibodies were frequently detected in sera from patients with chronic neutropenia in infancy, there were a small number of cases whose antibodies reacted specifically with the neutrophil

Received January 31, 1989; accepted May 8, 1989.

Reprint requests Masao Kobayashi, M.D., Department of Pediatrics, Hiroshima University School of Medicine, Kasumi 1-2-3, Minami-Ku, Hiroshima, 734 Japan. Supported in parts by Grants-in-Aid for Scientific Research from the Ministry of Education, Science and Culture of Japan.
}

antigens (4-9). Neutrophils possess several specific antigens: NA1, NA2, NB1, NB2 (9A), NCl (VAZ), ND1, and NE1. Among these antigens, NA antigen system of neutrophil is the diallelic, composed of NA1 with gene frequency of 0.337 , and NA2 with gene frequency of 0.663 in Caucasian populations (10-12). Neutrophil-specific antigens have been detected primarily by leukoagglutination and neutrophil immunofluorescence; however, the relationship between the results of these tests has not been well established.

In this report, we describe detailed investigations of two infants with persistent neutropenia caused by an autoantibody with antiNA1 specificity. The anti-NA1 specificity of the antibody was further studied comparing the results of indirect immunofluorescence test and leukoagglutination test, and determined by the selective reactivity with both autologous and allogeneic neutrophils that expressed NA1 antigen.

\section{MATERIALS AND METHODS}

Case report 1, Y.Y. A 10-mo-old female infant was admitted to our hospital for the evaluation of persistent neutropenia. She was delivered to her 24-y-old primigravida mother after an uncomplicated full-term pregnancy. Her growth and development was normal. At the age of $8 \mathrm{mo}$, she had suffered from an upper respiratory tract infection. The complete blood cell count showed a total WBC count of $7600 / \mathrm{mm}^{3}$ with an ANC of $0 /$ $\mathrm{mm}^{3}$. Hb, lymphocyte, and platelet counts were normal. There was no history of drug ingestion or blood transfusions. Both parents were healthy and were not related. On admission, the patient's total WBC cell count was $8600 / \mathrm{mm}^{3}$, with an ANC of $0 / \mathrm{mm}^{3}$. During her hospitalization, total WBC count ranged from 6000 to $14500 / \mathrm{mm}^{3}$, with an ANC of $0-150 / \mathrm{mm}^{3}$. Bone marrow aspiration showed a myeloid:erythroid ratio of 1.85 , with normal cellularity and normal myeloid precursors, but a profound decrease of segmented neutrophils $(0.4 \%)$. The serum concentrations of Ig were: IgG $1081 \mathrm{mg} / \mathrm{dL} ; \operatorname{IgA} 43 \mathrm{mg} / \mathrm{dL} ; \mathrm{IgM}$ $205 \mathrm{mg} / \mathrm{dL}$, and IgE less than $25 \mathrm{IU} / \mathrm{mL}$. The levels of serum complement, including $\mathrm{CH} 50, \mathrm{C} 3$, and $\mathrm{C} 4$ were normal. Circulating immune complexes in the serum were not detected. Autoantibodies including RA test, DNA test, antinuclear antibody, and antithyroid test were negative. In colony assay of bone marrow cells according to our method (13), all components of CFU in culture (CFUc) such as CFUc-G, CFUc-GM, and CFUc$\mathrm{M}$ grew normally.

Case report 2, T.N. A 9-mo-old male infant with a persistent neutropenia for 2 mo was referred to our hospital for further evaluation. He was born to his 22 -y-old primigravida mother after a full-term, uneventful pregnancy, labor, and delivery. At 46 
enterocolitis, he was found to be neutropenic with ANC of 138/ $\mathrm{mm}^{3}$. On admission, complete blood cells counts were; red blood cells $532 \times 10^{4} / \mathrm{mm}^{3}$; WBC $10200 / \mathrm{mm}^{3}$; and ANC of $102 /$ $\mathrm{mm}^{3}$. He had never received blood transfusions. During his hospitalization, total WBC count ranged from 5800 to $10200 /$ $\mathrm{mm}^{3}$, with an ANC of $0-180 / \mathrm{mm}^{3}$. Bone marrow aspiration revealed a normal cellularity and morphology but percentage of segmented neutrophils decreased to $0.8 \%$. Biochemical profile, serum Ig, and serum complements were all within the normal range. No circulating immune complexes or autoantibodies, other than antineutrophil antibody, were detected.

Preparation of neutrophils. Human neutrophils were prepared with EDTA or heparinized venous blood by centrifugation on sodium diatrizoate-Ficoll gradients followed by dextran sedimentation as previously described (14). Contaminating red blood cells were eliminated by hypotonic lysis. Cells were washed and suspended to the desired concentration in PBS without metals. Preparations contained more than $95 \%$ neutrophils.

GIIFT. GIIFT was performed by the modification of the method of Verheugt et al. (15). Prepared neutrophils, as described above, were fixed with $1 \%$ paraformaldehyde in PBS for $5 \mathrm{~min}$ and washed twice in PBS. The cells were incubated with test serum for $30 \mathrm{~min}$, washed three times in PBS, and then incubated with fluorescein isothiocyanate-labeled $\mathrm{F}\left(\mathrm{ab}^{\prime}\right)_{2}$ fragments of goat antihuman polyvalent Ig, IgG, IgM, and IgA (Tago Inc., Burlingame, CA), appropriately diluted in PBS for $30 \mathrm{~min}$ at $4^{\circ} \mathrm{C}$, respectively. After washing, this cell suspension was examined with an immunofluorescent microscope or with a flow cytometry. The positive reactions may be graded from - to +++ according to the intensity of the membrane-associated fluorescence.

$M-L A T$. M-LAT was done by a modification of the method of McCullough et al. (7). Neutrophils, prepared as described above by EDTA, were suspended in PBS with $0.4 \%$ EDTA and $0.5 \%$ BSA (Sigma Chemical Co., St. Louis, MO) and incubated with test serum in Terasaki trays at $37^{\circ} \mathrm{C}$ for 6 to $24 \mathrm{~h}$. The reactions were stopped by the addition of one drop of $6 \%$ acetate and examined using an inverted phase microscope. The result of an agglutination was scored from - to +++ .

Absorption experiments. According to the method of Helmerhorst et al. (16), the absorption was performed by incubating 2.5 $\times 10^{7}$ leukocytes or $2.5 \times 10^{8}$ platelets with $0.5 \mathrm{~mL}$ serum (or an equivalent ratio antiserum/number of cells) at $37^{\circ} \mathrm{C}$ for 30 min. The absorbed serum was recovered after 5 min centrifugation at $10000 \times g$ and tested against the same cells for the GIIFT and M-LAT.

\section{RESULTS}

The results of the initial GIIFT and M-LAT performed at the time of diagnosis are shown in Table 1. In the GIIFT, the sera from two patients reacted with neutrophils when polyvalent antiIg and anti-IgG were used as second antibodies. The reactions of anti-IgM and anti-IgA were all negative. Representative positive histogram of flow cytometry is shown in Figure 1. In contrast, M-LAT showed both positive and negative reactivities against different neutrophils.

The sera from patients and their mothers were examined against neutrophils from both parents in the GIIFT and M-LAT

Table 1. Results of GIIFT and M-LAT

\begin{tabular}{cccccc}
\hline & \multicolumn{5}{c}{ GIIFT* } \\
\cline { 2 - 5 } Serum & Anti-Ig & Anti-IgG & Anti-IgM & Anti-IgA & M-LAT \\
\hline Patient 1 & +++ & +++ & - & - & $-\sim+++$ \\
Patient 2 & ++ & ++ & - & - & $-\sim++$ \\
\hline
\end{tabular}

* GIIFT was performed as described in "Materials and Methods" using various goat-antihuman Igs $\mathrm{F}\left(\mathrm{ab}^{\prime}\right)_{2}$, such as antihuman polyvalent Ig (anti-Ig), anti-IgG, anti-IgM, and anti-IgA.
(Table 2). The sera from two patients reacted with neutrophils from their parents in both the GIIFT and the M-LAT. However, all reactions in the sera from their mothers were negative against the same neutrophils, suggesting that the antibodies detected in the patients' sera might be an autoantibody.

To confirm the results shown in Table 1, these sera were tested against 17 randomly selected unrelated donors whose NA antigen was determined by the reactivity with panel serum in the $\mathrm{M}$ LAT. The antigenicity in neutrophils could be grouped based on a biallelic system of NA antigen; 1) NA1/NA1, 2) NA1/NA2, and 3) NA2/NA2. The results are given in Table 3. A positive reaction was obtained with the GIIFT against all neutrophils when anti-human $\operatorname{IgG~} \mathrm{F}\left(\mathrm{ab}^{\prime}\right)_{2}$ was used as the second antibody. The resultant antibodies were IgG. In the M-LAT, the patients' sera agglutinated all of the $\mathrm{NAl}^{+}$neutrophils and none of the four NA-1 ${ }^{-}$samples. The titer of agglutinations in the M-LAT against NA1/NA2 neutrophils was lower than that against the NA1/NA1 ones. No lymphocytotoxic antibodies could be demonstrated in the patient's sera with the standard National Institutes of Health technique (data not shown). From these results, it appears that the antibodies detected in the sera from two cases were specific for the NAI antigen.

To determine further specificity for anti-NA1 antibody, the absorption experiments were done (Table 4). The patients' sera were completely absorbed with NA1/NA1 neutrophils, but not with NA2/NA2 ones in the M-LAT. In the GIIFT, the reactivity of the sera absorbed with NA1/NA1 became negative, but a weak positive reaction was retained in the sera absorbed with NA2/NA2 neutrophils. These results suggest that the absorption experiment would be necessary to obtain the specificity of NA1 antigen in the GIIFT. No absorption of the patients' sera with

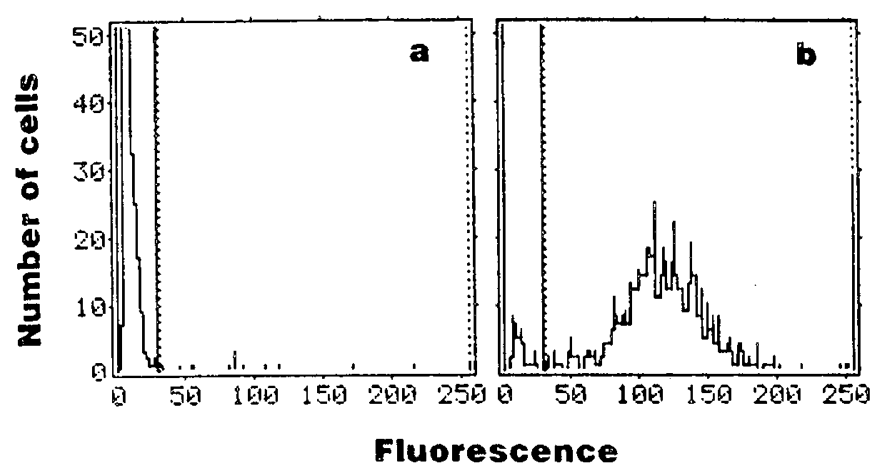

Fig. 1. Representative histogram of a flow cytometry in granulocyte indirect immunofluorescence test. $\mathrm{NA}^{+}{ }^{+}$neutrophils fixed with $1 \%$ paraformaldehyde were incubated with normal serum $(a)$ or serum from patient $1(b)$ and incubated with fluorescein isothiocyanate-labeled antihuman $\operatorname{IgG~} \mathrm{F}\left(\mathrm{ab}^{\prime}\right)_{2}$. Fluorescence analysis was performed on a OrthoCytoron flow cytometer (Ortho Diagnostic Systems, Tokyo, Japan). This fluorescent intensity $(b)$ is expressed as +++ .

Table 2. Reactivity of patients' and their mothers' sera in GIIFT and $M-L A T$

\begin{tabular}{ccccc}
\hline & \multicolumn{3}{c}{ GIIFT } & \multicolumn{2}{c}{ M-LAT } \\
\cline { 2 - 5 } Neutrophils & \multicolumn{4}{c}{ Patients' sera } \\
\cline { 2 - 5 } Mother & Patient 1 & Patient 2 & Patient 1 & Patient 2 \\
Father & ++ & ++ & +++ & ++ \\
& & + & + & + \\
& \multicolumn{4}{c}{ Mothers' sera } \\
\cline { 2 - 5 } & Patient 1 & Patient 2 & Patient 1 & Patient 2 \\
\hline Mother & - & - & - & - \\
Father & - & - & - & - \\
\hline
\end{tabular}


allogeneic red blood cells, platelets, and lymphocytes was observed (data not shown).

After diagnosis, the patients have been followed by the serial neutrophil counts. During the neutropenic periods, both patients experienced mild infections, but these were adequately managed with antibiotics. When absolute neutrophil counts rose temporarily in the course of the infection, autoreactivity of previously

Table 3. Reactivity in GIIFT and M-LAT of patients' sera against neutrophils from random donors determined $N A$ antigen

\begin{tabular}{cccccc}
\multicolumn{9}{c}{ antigen } & \multicolumn{2}{c}{ M-LAT } \\
\cline { 2 - 3 } \cline { 5 - 5 } Neutrophils & Patient 1 & Patient 2 & Patient 1 & Patient 2 \\
\cline { 2 - 3 } A:NA1/NA1 & & & & \\
1 & +++ & +++ & +++ & ++ \\
2 & +++ & +++ & +++ & ++ \\
3 & +++ & NT* & +++ & NT \\
4 & +++ & NT & +++ & NT \\
5 & +++ & NT & +++ & NT \\
6 & +++ & NT & +++ & NT \\
7 & +++ & NT & +++ & NT \\
8 & +++ & NT & +++ & NT \\
9 & +++ & NT & +++ & NT \\
& & & & \\
B:NA1/NA2 & & & & \\
1 & ++ & ++ & ++ & + \\
2 & ++ & ++ & + & + \\
3 & ++ & NT & + & NT \\
4 & ++ & NT & ++ & NT \\
C:NA2/NA2 & & & & & \\
1 & ++ & ++ & - & - \\
2 & ++ & ++ & - & - \\
3 & ++ & NT & - & NT \\
4 & ++ & NT & - & NT \\
\hline
\end{tabular}

* Not tested.

Table 4. Reactivity in GIIFT and M-LAT of absorbed sera with $N A 1 / N A 1$ or $N A 2 / N A 2$ neutrophils against the same neutrophils

\begin{tabular}{|c|c|c|c|c|}
\hline \multirow[b]{2}{*}{ Neutrophils } & \multicolumn{2}{|c|}{ GIIFT } & \multicolumn{2}{|c|}{ M-LAT } \\
\hline & Patient 1 & Patient 2 & Patient 1 & Patient 2 \\
\hline \multicolumn{5}{|l|}{ A. original sera } \\
\hline NA1/NA1 & +++ & ++ & +++ & ++ \\
\hline NA2/NA2 & ++ & + & - & - \\
\hline \multicolumn{5}{|c|}{$\begin{array}{l}\text { B. sera absorbed with } \\
\text { NA1/NA1 neu- } \\
\text { trophils }\end{array}$} \\
\hline NA1/NA1 & - & - & - & - \\
\hline NA2/NA2 & - & - & - & - \\
\hline \multicolumn{5}{|c|}{$\begin{array}{l}\text { C. sera absorbed } \\
\text { with NA2/NA2 } \\
\text { neutrophils }\end{array}$} \\
\hline NAl/NA1 & +++ & ++ & +++ & ++ \\
\hline NA2/NA2 & \pm & \pm & - & - \\
\hline
\end{tabular}

Table 5. Reactivity in GIIFT and M-LAT of patients' sera against their own neutrophils

\begin{tabular}{ccc} 
Neutrophils & GIIFT & M-LAT \\
\hline Patient 1 & +++ & +++ \\
Patient 2 & +++ & +++ \\
\hline
\end{tabular}

stored sera from both patients was tested against their own neutrophils (Table 5). The sera from two patients reacted with their own neutrophils in both the GIIFT and M-LAT, suggesting that their neutrophils possessed the NA1 antigen. Similar results against their own neutrophils were obtained after the spontaneous resolution of neutropenia.

\section{DISCUSSION}

Autoimmune neutropenia is being diagnosed with increasing frequency and may prove to be the most common cause of chronic neutropenia in infancy (3). We reported here two cases of nontransfused infant with persistent neutropenia due to autoantibody against neutrophil specific antigen NA1. The NA1 specificity of the antibodies was confirmed by the reactivity with $\mathrm{NA}^{+}$and $\mathrm{NA}^{-}$neutrophils, and by the absorption tests in the GIIFT and the M-LAT.

Several methods are available and compared to detect neutrophil antibodies $(2,4,7,12,17,18)$. McCullough et al. (7) reported that the antibodies detected by agglutination were clinically more significant with neutropenia than by granulocytotoxicity and staphylococcal protein A assay. Verheugt et al. (4) suggested that strongly positive reactions in immunofluorescence were obtained not only with antisera containing agglutinins or granulocytotoxins, but also with some sera that did not react in either the agglutination or cytotoxicity test. In addition, immunofluorescence test appears to be a simple and sensitive method that allows us to study immunochemical characteristics of antibodies (19). In this study, antibodies detected with the agglutination test clearly discriminated between $\mathrm{NAl}^{+}$and $\mathrm{NAl}^{-}$neutrophils. In contrast, the immunofluorescence test showed the positive reactions against both $\mathrm{NAl}^{+}$and $\mathrm{NAl}^{-}$neutrophils and the specificity for anti-NA1 was found in the results of the sera absorbed with NA1/NA1 neutrophils. Furthermore, some antibodies (such as NB2, 5a, 5b) have been found to be detected only by the agglutination and not by the immunofluorescence test $(15,20)$. These evidences suggested that a combination of agglutination and immunofluorescence techniques is recommended for investigation of neutrophil antibodies against the neutrophil specific antigen.

Although NA antigen system was serologically well defined, precise characterization of this antigen is not yet known. To characterize NA-1 antigen, we performed an immunoblot with sera from the patients according to the methods of Laemmli (21), Towbin et al. (22), and Stricker et al. (23). However, no specific band was obtained by anti-NA1 serum against the lysate from $\mathrm{NA}^{+}$neutrophils in various conditions (data not shown). Therefore, it might be difficult to recognize the NAl antigen under these conditions.

There may be differences in natural history of the neutropenia depending on pathophysiologic mechanisms $(1,2,12,25)$. Our patients have been followed from 12 to 24 mo after diagnosis. It is notable that the increase of neutrophil counts has well correlated with the decrease of the titer of antineutrophil antibodies. Conway et al. (24) reported the natural history of autoimmune neutropenia. The illness resolved spontaneously within $41 \mathrm{mo}$ and resolution of neutropenia paralleled the disappearance of neutrophil autoantibodies.

Thus, the demonstration of antibodies by the combination of sensitive assays has important diagnostic and prognostic value because it indicates a benign course. Further investigation using several assay systems for detecting the antibodies might clarify the precise nature of the neutrophil-specific antigen and the relationship between the serologic reactivity of antibodies and their clinical significance.

Acknowledgments. The authors thank Dr. Mareen Sakura for assistance in preparing the manuscript and Drs. S. Ohto and T. Juji (Tokyo University) for a gift of pannel serum against neutrophil antigen. 


\section{REFERENCES}

1. Weetman RM, Boxer LA 1980 Childhood neutropenia. Pediatr Clin North Am 27:361-375

2. Boxer LA 1981 Immune neutropenias: clinical and biological implications. Am J Pediatr Hematol Oncol 3:89-96

3. Lalezari P, Khorshidi M, Petrosava M 1986 Autoimmune neutropenia of infancy. J Pediatr 109:764-768

4. Verheugt FWA, von dem Borne AEGK, van Noord-Bokhorst JC, Engelfriet CP 1978 Autoimmune granulocytopenia: the detection of granulocyte autoantibodies with the immunofluorescence test. Br J Haematol 39:339-350

5. Valbonesi M, Campelli A, Marazzi MG, Cottafava F, Jannuzzi C 1979 Chronic autoimmune neutropenia due to anti-NA1 antibody. Vox Sang 36:9-12

6. Priest JR, Clay ME, McCullough J, Ramsay NKC, Lalezari P, Krivit W 1980 Transient autoimmune neutropenia due to anti-NA1 antibody. Am J Pediatr Hematol Oncol 2:195-199

7. McCullough J, Clay ME, Priest JR, Jensen NJ, Lau S, Noreen HJ, Krivit W, Lalezari P 1981 A comparison of methods for detecting leukocyte antibodies in autoimmune neutropenia. Transfusion 21:483-492

8. Madyastha PR, Kyong CU, Darby CP Jr, Genco PV, Madyastha KR, Glassman $A B$, Fudenberg H 1982 Role of neutrophil antigen NA1 in an infant with autoimmune neutropenia. Am J Dis Child 136:718-721

9. Sabbe LJM, Claas FHJ, Langerak J, Claus G, Smit LWA, de Koning JH, Schreuder CH, van Rood JJ 1982 Group-specific auto-immune antibodies directed to granulocytes as a cause of chronic benign neutropenia. Acta Haematol 68:20-27

10. Lalezari P, Radel E 1974 Neutrophil-specific antigens: immunology and clinical significance. Sem Hematol 11:281-290

11. Lalezari P 1977 Neutrophils antigens: immunology and clinical significance. In: Greenwalt TJ, Jamieson GA (eds) The Granulocyte: Function and Clinical Utilization, Progress in Clinical and Biological Research. Alan R Liss Inc, New York, pp 209-225

12. McCullough J 1983 Granulocyte antigen systems and antibodies and their clinical significance. Hum Pathol 14:228-234
13. Kawaguchi $Y$, Kobayashi M, Tanabe A, Hara M, Nishi Y, Usui T, Nagai S, Nishibayashi Y, Nagao K, Yokoro K 1985 Granulopoiesis in patients with congenital neutropenia. Am J Hematol 20:223-234

14. Kobayashi M, Tanaka T, Usui T 1982 Inactivation of lysosomal enzymes by the respiratory burst of polymorphonuclear leukocytes. J Lab Clin Med 100:896-907

15. Verheugt FWA, von dem Borne AEGK, Decary F, Engelfriet CP 1977 The detection of granulocyte alloantibodies with an indirect immunofluorescence test. Br J Haematol 36:533-544

16. Helmerhorst FM, van Oss CJ, Bruynes ECE, Engelfriet CP, von dem Borne AEGK 1982 Elution of granulocyte and platelet antibodies. Vox Sang 43:196-204

17. Harmon DC, Weitzman SA, Stossel TP 1980 A staphylococcal slide test for detection of antineutrophil antibodies. Blood 56:64-69

18. Thompson JS, Overlin VL, Herbick JM, Severson CD, Claas FHJ, 'Amaro JD, Burns CP, Strauss RG, Koepke JA 1980 New granulocyte antigens demonstrated by microgranulocytotoxicity assay. J Clin Invest 65:14311439

19. Verheugt FWA, von dem Borne AEGK, van Noord-Bokhorst JC, van Eleven $\mathrm{EH}$, Engelfriet CP 1978 Serological and immunocytological properties of granulocyte antibodies. Vox Sang 35:294-303

20. Lalezari P, Petrosova M, Jiang AF 1982 NB2, an allele of NB1 neutrophic specific antigen; relationship to 9 a. Transfusion $22: 433$

21. Laemmli UK 1970 Cleavage of structural proteins during the assembly of the head of bacteriophage T4. Nature 227:680-685

22. Towbin H, Staehelin T, Gordon J 1979 Electrophoretic transfer of proteins from polyacrylamide gels to nitrocellulose sheets: procedure and some applications. Proc Natl Acad Sci USA 76:4350-4354

23. Stricker RB, Abrams DI, Corash L, Shuman MA 1985 Target platelet antigen in homosexual men with immune thrombocytopenia. $\mathrm{N}$ Engl J Med 313:1375-1380

24. Conway LT, Clay ME, Kline WE, Ramsay NKC, Krivit W, McCullough J 1987 Natural history of primary autoimmune neutropenia in infancy. Pediatrics 79:728-733 